\title{
La granada, símbolo de reyes y de la monarquía española
}

\author{
Sebastián García Garrido
}

Se recopilan y analizan los diferentes símbolos a que dieron lugar las ramas de granado y su fruto como símbolo y emblema personal de una serie de reyes de España, o vinculados directamente con ellos, desde la segunda mitad del siglo XIV hasta todo el siglo XVI. La singularidad de este fruto, cuya corola tiene la forma de la corona de los reyes antiguos y el atractivo del interior, que deja ver cuando está maduro, ejerció un poderoso encanto en estos monarcas. El simbolismo de la unidad que muestra de manera natural y su vinculación con el deseado Reino de Granada completaron ese atractivo que le introdujo en emblemas oficiales y en todo tipo de ornamentación hasta llegar a ser todavía imagen distintiva de la monarquía española.

The author describes an exhaustive análisis about iconographic reputation and diffusion of the fruits of pomegranate, whose crown appearance arose their symbolical context into Spanish Royal Imaginery and Heraldry between XIV-XVI centuries.

La forma y disposición de la corona real arcaica, la que traían los reyes de la antigüedad, curiosamente responde a la corola de la granada, que al mismo tiempo siempre se representa con ella hacia arriba, en contra de su disposición natural en el árbol y de la tradición de expresar este sentido natural en el resto de las interpretaciones frutales'. Este distintivo de quienes lideran un pueblo u ostentan el poder, bastante ligado a la divinidad, responde a la forma de la corona que describe la Biblia para el rey David².

GARCÍA GARRIDO, Sebastián: "La granada, símbolo de reyes y de la monarquía española", en Boletín de Arte n 25, Universidad de Málaga, 2004, págs. 127-148. 
La granada, como simbolo, ha tenido importantes acepciones como atributo de cualidades de la mitología clásica en Grecia y en Roma, además de su papel como símbolo de la castidad y de la resurrección en el cristianismo. Destaca en la Edad Media la producción de tejidos en la península, producto en muchos casos de la rica manufactura mozárabe. El motivo más destacado de estas telas, muy apreciadas en el occidente europeo, era la forma de la granada. La granada llega a ser un motivo clásico en el Renacimiento hasta el punto de que el damasco antiguo se distingue, por la reproducción de este motivo. En cambio, es a partir de la Edad Moderna, con el Renacimiento en España y con la trascendental conquista del Reino de Granada a los árabes, cuando la granada adquiere un mayor protagonismo iconográfico. Aunque el nuevo significado no implica la desaparición de los anteriores, sino que subyacen como un sustrato más o menos perceptible. Sin embargo, existe una jerarquia que hace prevalecer el sentido más reciente.

La granada es símbolo también del propio rey Salomón, no sólo porque según la Biblia $^{3}$ éste presumía de tener un huerto de granados sino porque es uno de los objetos más significativos, junto a las tablas de los diez mandamientos, encontrados en su primer templo construido en Jerusalén. Se trata de una pequeña granada de marfil, con una inscripción en hebreo antiguo que dice sagrada donación por los sacerdotes de la Casa de Yavé (FIG. 1). Curiosamente en una tumba ibera encontramos la granada en forma de pequeños frascos, que contendrian ungüentos 0 aromas (FIG. 2) ${ }^{4}$ y sobre los que la propia leyenda que ofrece el museo se estima procedian de Oriente Medio. Curiosamente este frasco es muy similar a otro expuesto en el museo del Louvre ${ }^{5}$, originario de Egipto, igualmente realizado en barro cocido y policromado de rojo, sólo que datado unos mil años antes. La policromía de ambos frascos está realizada con el mismo color. Sin embargo, el recipiente egipcio, reproduce un dibujo que incluye líneas y motivos ornamentales, mientras en el ejemplar de Jaén se aplica de manera uniforme.

\footnotetext{
${ }^{1}$ Véase más adelante el sentido que da Cirlot al concepto de la corona, cuando hablamos de la corona de la Reina Católica y la orfebrería real.

${ }^{2}$ GUELFI CAMAJANI, P: Diccionario araldico (reedición de la publicada en Milán en 1940), Arnaldo Forni Editore, Bologna 1978, p. 181 y ss.

${ }^{3} \mathrm{Al}$ mismo tiempo, se hace referencia de lo que los niños judíos echaban de menos las refrescantes granadas de Egipto, en la travesía del desierto. De ahí que la granada sea un símbolo o motivo ornamental muy habitual en la cultura y el arte semita.

${ }^{4}$ Museo Provincial de Jaén. Cultura Íbera. Pequeñas vasijas de cerámica, halladas en la necrópolis de La Loma de Peinado (Casillas de Martos) ss. V-II a.C. Aunque los materiales expuestos deben fecharse en los ss. V-IV a.C.

-[La más estrecha y corona más alta].- "amphoriskos de pasta vítrea (tumba 3), posiblemente importados de Oriente, servían para contener ungüentos".

-[La más ancha y corona más baja].- "aryballos en forma de granada (tumba 4), originariamente estuvo pintado de rojo por los restos que perduran en la superficie".

${ }^{5}$ Está fechado entre 1425-1390 a. de C. Sully, sala 24, vitrina 13.
} 

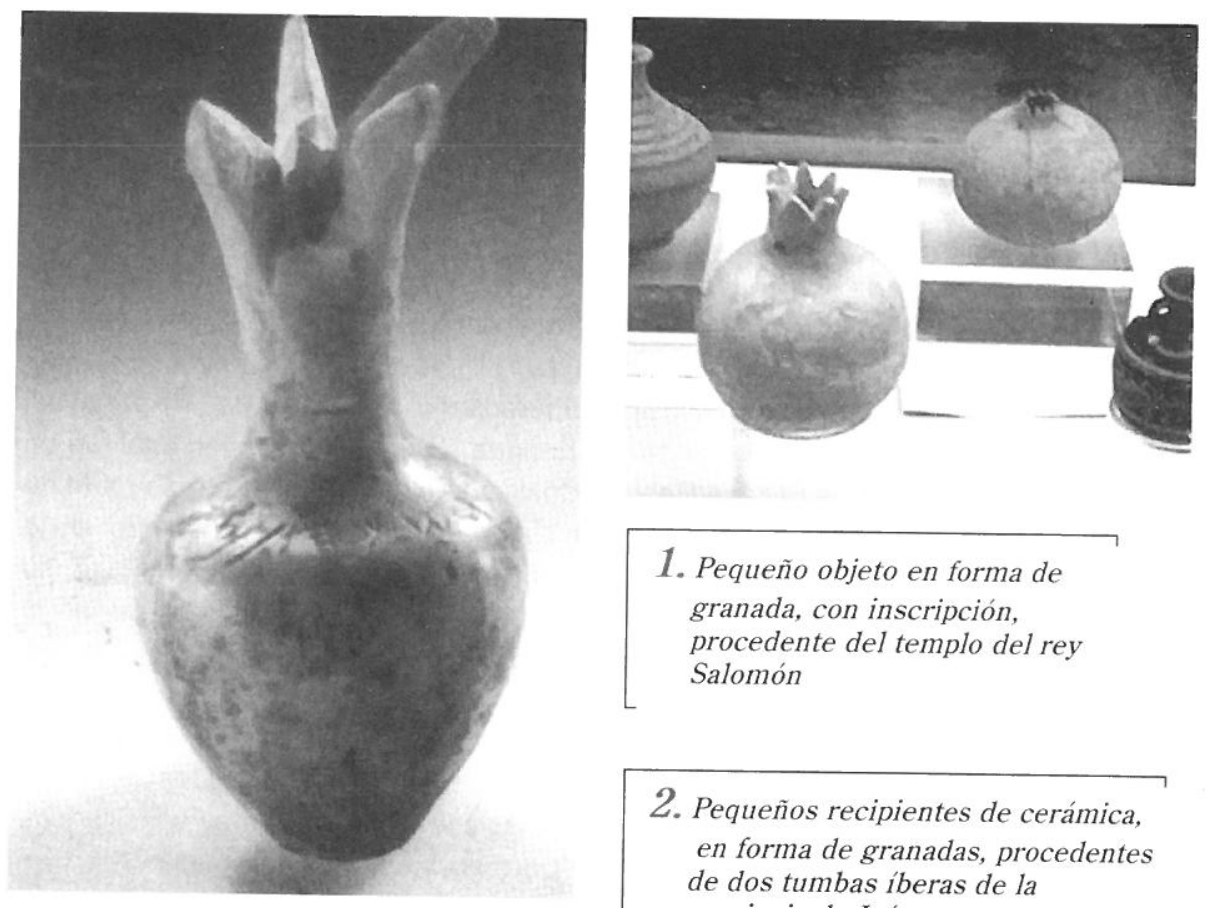

2. Pequeños recipientes de cerámica, en forma de granadas, procedentes de dos tumbas íberas de la provincia de Jaén

El diseño simbólico de la granada presenta dos momentos conceptuales claramente diferenciados: el primero es el que recurre a las tradiciones pagana y religiosa que este fruto ha tenido casi unánimemente en diferentes épocas y culturas del mundo, el segundo parte de la trascendental conquista del Reino de Granada a los árabes. Como sucede siempre en la evolución de un símbolo, el nuevo significado no implica la desaparición de los anteriores. Éstos subyacen como un sustrato más o menos imperceptible, pero siempre existe una jerarquía que hace prevalecer el sentido más reciente. Asi sucede -y de modo muy acusado- con la granada española a partir de los Reyes Católicos. Todas sus significaciones previas quedan subsumidas por la potencia semántica que tiene la conquista del reino nazarí. La propia configuración de la peculiar estructura de este fruto ha sido también simbolo tradicional de la unificación territorial: Las numerosas semillas contenidas dentro de su dura cáscara la convirtieron también en símbolo de la unidad de muchos bajo una misma autoridad (bien de la iglesia o de un monarca secular. La iconografía de la granada a partir de esta época de la historia de España ya nunca será la misma.

\footnotetext{
${ }^{6}$ HALL, J.: Diccionario de temas y símbolos artísticos, Alianza, Madrid 1974, p. 151. En la Biblia aparece ya como alusión a la unidad del universo. MORALES Y MARÍN, J.L.: Diccionario de iconología y simbología, Taurus, Madrid 1986, p. 162. "Pero el significado prevaleciente de la granada, debido a su forma y estructura interna, dominando sobre la impresión del color, es
} 
La primera vez que la granada es tomada como símbolo personal de un rey de España es con Enrique I de Castilla (1204-1217), que traia ya el fruto de la granada rajado mostrando el interior? ${ }^{7}$. Es muy significativo que este símbolo de la granada lo adoptara ya el sucesor de Alfonso VIII, quien asumió por primera vez las armas de gules con el castillo de oro, como emblema heráldico de los reyes de Castilla.

Posteriormente sería Enrique IV (1425-1474), hermano mayor de Isabel la Católica, quien volvería a adoptar la granada igualmente como empresa personal. Se trata de una época en la que surgía la necesidad de diferenciar el escudo de armas, como distintivo territorial y también como algo hereditario, de la identidad personal del rey, en este caso. La granada adoptada por Enrique IV como divisa ${ }^{8}$ personal fue un distintivo que se empleó en la casa Real de Castilla -cuya costumbre puede partir de sus contactos con la casa real inglesa- y en algunos nobles de alto rango en la segunda mitad del siglo XIV y durante el XV, a la vez que la heráldica culminó su evolución ${ }^{9}$, desde la simplicidad de la señal que debía percibirse claramente en la distancia pasa a ser un elemento ornamental que enriquece su aspecto.

La divisa se considera perfecta si consta de 'cuerpo' y 'alma' o, por el contrario, imperfecta si sólo tiene cuerpo -figura- o sólo alma -mote o leyenda-. Generalmente se empleaban dos versiones de la divisa, una más compleja y otra más sencilla y de menor tamaño, adecuada para repetirla en un friso, como motivo continuo en un fondo, etc.

Las dos formas en que aparece el emblema personal de Enrique IV son, dos ramas frutadas de granadas, rodeando el escudo: así están en la reproducción de sus armas en una vidriera del Alcázar de Segovia (FIG. 3), en algunas monedas, también en Segovia en el patio del palacio de San Martín y en varios lugares del monasterio de San Antonio el Real, en la portada del castillo de Cuéllar -donde encontramos al mismo tiempo el mote o alma de éste: 'Agridulce es reinar'; mientras la granada sola está en la cimera que trae una reproducción de su imagen ecuestre

el del adecuado ajuste de lo múltiple y diverso en el seno de la unidad aparente". CIRLOT, J.E., Diccionario de símbolos, Labor, Barcelona 19856, p. 228.

${ }^{7}$ OCHOA DE OLZA, E.-RAMOS, M.: Usos heráldicos en Navarra, Gobierno de Navarra: Dirección General de Cultura/Institución Príncipe de Viana, Pamplona 1990, p. 56.

${ }^{8}$ La divisa es un distintivo sencillo que tiene la función de servir para reconocer a su titular. Nacen en las orillas del Loira y del Rin -norte de Francia, Borgoña y Flandes y de allí se extienden primeramente a Inglaterra y Alemania. Posteriormente pasan a España e Italia. En Inglaterra, denominadas badges o insignias han perdurado hasta nuestros días. A finales del s. XV desaparecen las divisas en España, con la llegada del Renacimiento y la nueva dinastía y, en cierto modo, son sustituidas por las denominadas empresas, que son más elaboradas y adquieren un carácter filosófico-moral más acentuado aludiendo a un fin o un objetivo que se marca o distingue a su titular. CEBALLOS-ESCALERA, A.: "Las divisas en la heráldica castellana del siglo XV", en Hidalguía núm. 192, Madrid sept.-oct. 1985, p. 666 y ss.

9 MENÉNDEZ PIDAL DE NAVASCUÉS, F. Heráldica Medieval Española. I. La Casa Real de León y Castilla, Hidalguía, Madrid 1982, p. 191. 

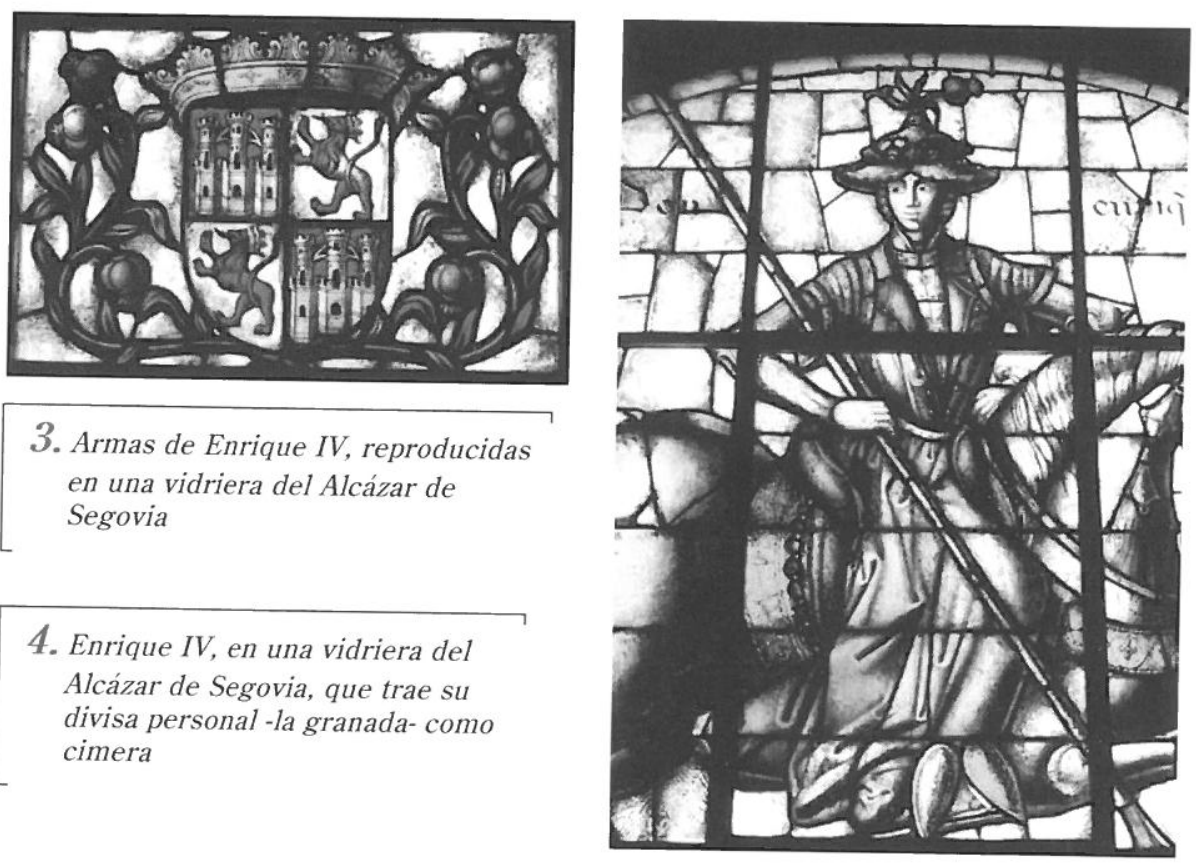

3. Armas de Enrique IV, reproducidas en una vidriera del Alcázar de Segovia

\section{Enrique $I V$, en una vidriera del} Alcázar de Segovia, que trae su divisa personal -la granada- como cimera

(FIG. 4), bajo el león en algunas monedas y también en el guión y la bandera ${ }^{10}$ que se encontraron del rey en el Alcázar de Segovia" En estas enseñas se aprecian claramente los colores simbólicos que personalizan esta divisa real, en la que el campo es de sinople y la granada de oro, rajada de gules. El mismo color del paño y la granada, repetida en cada una de sus esquinas -sólo que en su color natural- sería el que definió el posterior estandarte de la Guardia Vieja de Castilla (1493-1503), a raíz de la conquista de Granada, que traía en el centro el escudo de los Reyes Católicos, aún sin la granada entada en punta ${ }^{12}$. Inspirado, a su vez, en este último es sin duda el estandarte de caballería que se encuentra en la catedral de Granada ${ }^{13}$, de época posterior (1580) como indica en este caso su escudo, que trae ya las armas

\footnotetext{
10 "una bandera pequeña de guión, de tafetán verde, con una granada y con la divisa del rey don Enrique (...) y otra bandera de tafetán verde con la divisa de las granadas". Según consta en el inventario de Gaspar Gricio por mandato de la Reina Católica, en el Archivo General de Simancas, Patronato Real. Transcrito por ESCUDERO DE LA PEÑA, J.M.: "Enseñas y banderas durante la antigüedad y la Edad Media, particularmente en España", en Museo Español de Antigüedades, t. IX, pp. 575-586.

${ }^{11}$ CEBALLOS-ESCALERA, A.: op. cit., pp. 671-672.

${ }^{12}$ Así la vemos en el Álbum de la Infantería Española del Conde de Clonard, reproducida en: CALVO PÉREZ, J.L.-GRÁVALOS GONZÁLEZ, L.: Banderas de España, Silex, Vitoria 1983, p. 49.

${ }^{13}$ Ibidem, p. 77.
} 


S.:articulos Sebastian Garcia Garrido
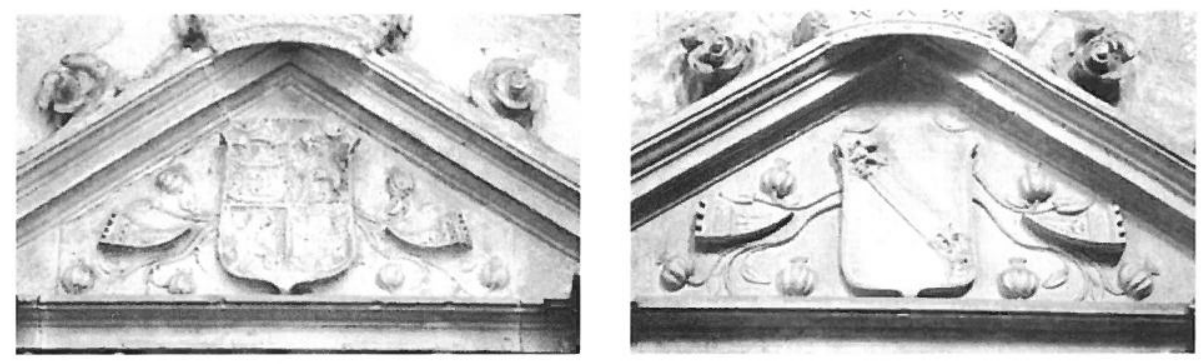

5 y 6. Armas del Reino y armas personales de Juan II, respectivamente, con ramas de granado y con las escamas como divisa personal

de Portugal. En este caso se incorpora una quinta figura de la granada que se superpone en el escudo sobre la zona que ocuparia el entado en punta incorporado ya definitivamente a estas armas.

En la entrada a la cartuja de Miraflores, en las cercanías de Burgos, mandada construir por Juan II -padre de Enrique IV y de la Reina Católica- encontramos las ramas de granadas, alrededor de las armas del monarca, en los tímpanos de las puertas laterales del altar mayor, donde se encuentra su sepulcro (FIGS 5 y 6 ). Pero el detalle más interesante de este complejo monumental es la corona real de granadas (FIG. 7) que timbra las armas de su segunda esposa Isabel de Portugal, en escudo partido del cuartelado de Castilla y León con Portugal (brisado de lambel que afirma que el titular no es el soberano $)^{14}$. Es un modelo similar a una de las coronas de la Reina Católica que comentamos más adelante. No encontramos una explicación ni a la ubicación en la entrada del convento de las armas de la segunda esposa ${ }^{15} \mathrm{ni}$ a que vengan acompañadas por una divisa, que es personal, atribuible únicamente a las armas de su esposo. En el altar mayor de la iglesia si que se encuentran perfectamente organizadas las armas de uno y otro titular del sepulcro principal. En cambio, la portada de la iglesia reproduce dos escudos y ambos sólo del rey, el cuartelado de Castilla y León y por otro lado la banda engolada, que empleaba al

\footnotetext{
${ }^{14}$ Alrededor del escudo se encuentran las escamas características de la divisa personal de su esposo, como se encuentran en el resto de las armerías del mismo en el edificio y labradas en los ropajes de su escultura yacente.

${ }^{15}$ El proyecto de la cartuja lo encarga Juan II a Juan de Colonia. Pero el gran impulso en la construcción del convento y especialmente el encargo de los sepulcros y el altar mayor son obra de Isabel la Católica. En 1483 la reina se desplaza a Miraflores y, tras un paréntesis en la dirección de la obra de Garci Fernández de Matienzo, pone a cargo del proyecto a Simón de Colonia, hijo del arquitecto originario. Para los sepulcros y el altar trae a Gil de Silóe que acababa de terminar el Colegio de San Gregorio en Valladolid. YARZA LUACES, J.: Los Reyes Católicos. Paisaje artístico de una monarquía, Nerea, Madrid 1993, pp. 55 y 56.
} 


\section{Armas de Isabel de Portugal timbradas de corona de granadas, segunda esposa de Juan II y madre de Isabel la Católica}

mismo tiempo como armas personales, acompañados ambos de las escamas (FIG. 8). En el tímpano que culmina los pies de esta nave principal y única de la iglesia se encuentran, también inexplicablemente, las armas de la primera esposa doña María de Aragón, partido del cuartelado de Castilla y León con Aragón ${ }^{16}$.

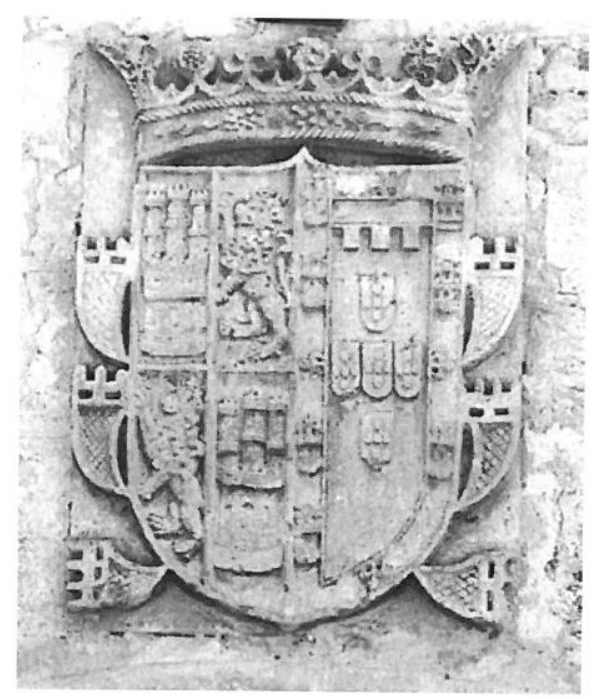

Esta divisa de la granada se incorpora a las armerías también como cimera, así está en el retrato de Enrique IV del Códice de la Genealogía de los Reyes de Castilla (1456), realizado por Alonso de Cartagena ${ }^{17}$ y en el que está basada la vidriera de su residencia principal, el Alcázar de Segovia (FIGS 3 y 4).

Las armas de Enrique IV las tenemos en la monumental fachada de la llamada Casa del Cordón, perteneciente a los Condestables de Castilla y donde los Reyes Católicos recibieron a Colón de su segundo viaje (FIGS 9 y 10). El proyecto emprendido por su predecesor Juan II, de hacer ver a la alta nobleza que el poder del rey está por encima de ellos, se expresa ya iconográficamente en este hábito de sobreponer las armas reales a las propias del noble titular de la casa. En este caso, es evidente que el cuartelado de Castilla y León no representa el conocido contracuartelado de los Reyes Católicos. Son las ramas de granado que acompañan a éste las que definen una época anterior de la que datan las armas reales y, por tanto, su origen en la construcción de esta casa por parte de los Condestables de Castilla, Pedro González de Velasco y Mencía de Mendoza.

\footnotetext{
${ }^{16}$ Éstas, en un lugar bastante poco visible pueden ser un testimonio de la fase de la construcción de la obra que se realizara durante el reinado de Enrique IV, más que por su aportación personal por las considerables rentas que dejó Juan II para ello.

${ }^{17}$ Manuscrito de la Biblioteca de Palacio.
} 


8. Armas del Reino y
armas personales de
Juan II en portada
de la iglesia de la
cartuja de
Miraflores, donde
está su sepulcro
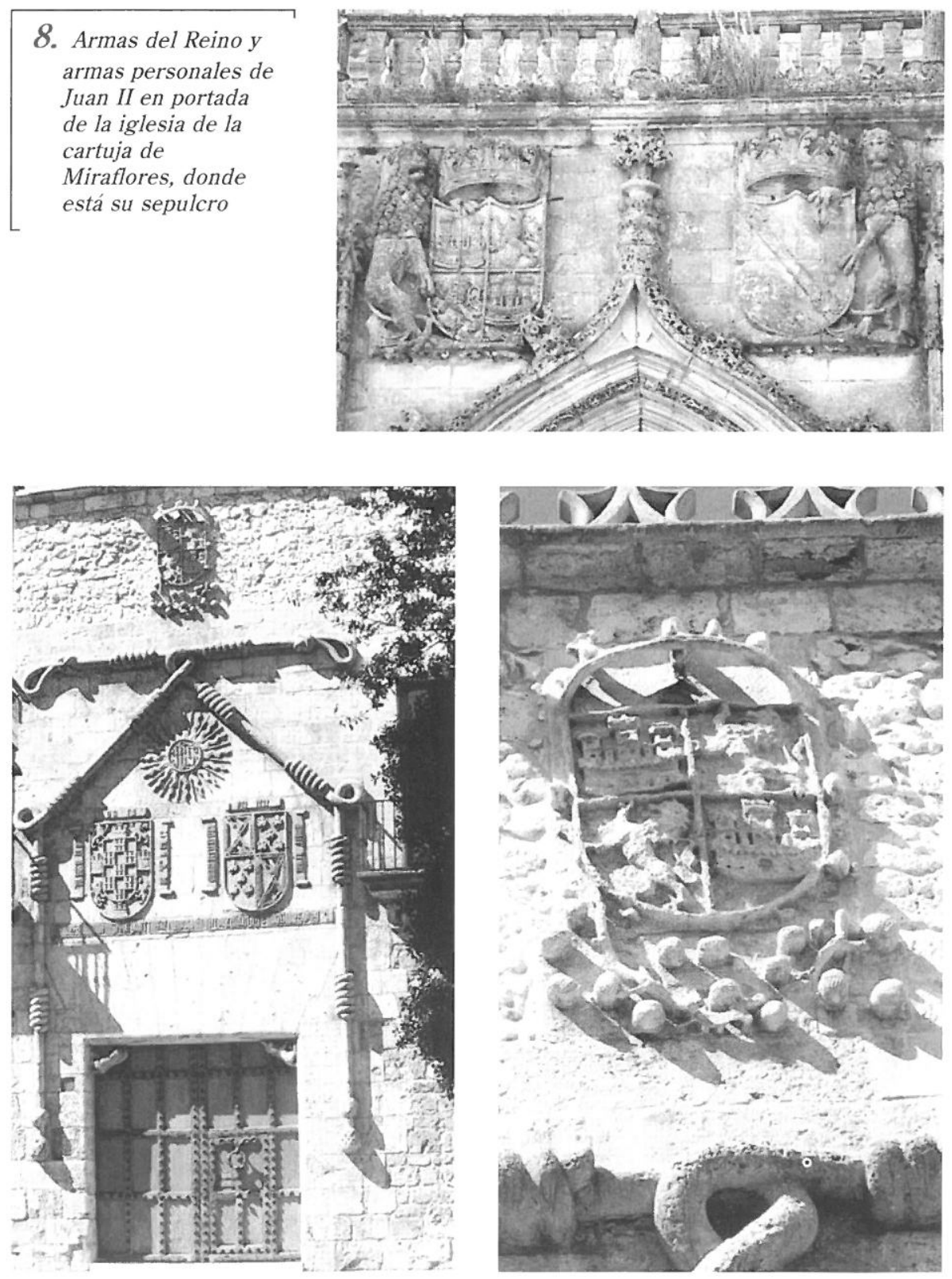

9 y 10. Portada de la Casa del Cordón, en Burgos, y detalle de las armas de Enrique IV culminando la misma 

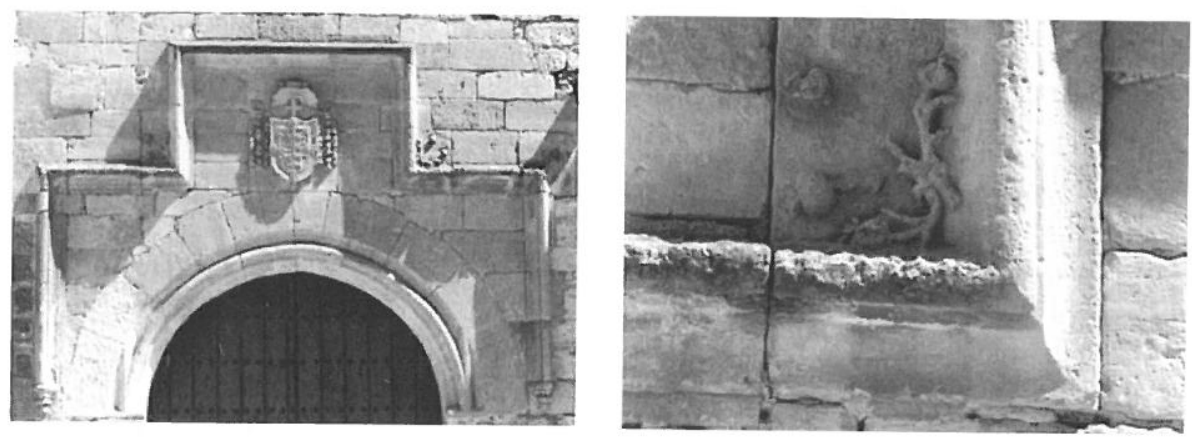

\section{1 y 12. Portada lateral de la iglesia de S. Sebastián en Toro y detalle de las granadas labradas en la misma}

Obras públicas e iglesias construidas entre este reinado y todo el siglo $\mathrm{XV}$ recogen las ramas de granado como motivo propio de su ornamentación. Es el caso de la iglesia de San Sebastián en Toro (FIGS. 11 y 12), que reproduce los ramos de granado en los entrantes del alfiz que remata la portada lateral y que recoge el escudo de armas del obispo que la promovió.

Algunos nobles de la época, simplemente incorporan las ramas de granadas alrededor de sus armas personales, vinculándolas claramente a la divisa de su rey. En el monasterio de Oña, la urna taraceada de don García trae ramas frutadas de granada. En la portada del palacio de los Duques de Arcos, procedente de Carmona y actualmente montada en uno de los accesos a los jardines de los Reales Alcázares, se representa una serie de granadas dispuestas en orla alrededor de la misma.

Los propios Reyes Católicos siguen empleando las ramas de granadas alrededor de su escudo, aunque contaran con otra divisa personal, pues tenian las suyas propias del yugo y las flechas, creadas por Nebrija. La granada llegaba a ser por tanto una especie de divisa de la casa real. Algunos, como Pedro Marcuello en su cancionero $^{18}$, la consideran distintivo personal junto al yugo y las flechas (FIG. 13). Incluso, se añade bordura de granadas en la versión de sus armas del misal llamado de la Reina Católica -en la Capilla Real de Granada-, que ya incorpora el cuartel de Granada. Sin embargo, en este ejemplar policromado observamos que los esmaltes difieren claramente de la divisa de Enrique IV. En un sello de Fernando el Católico ${ }^{19}$, rodeando sus armas, están igualmente las ramas de granado. Son numerosos los ornamentos con estas ramas en la fachada, el claustro y otros detalles en el monasterio de Santo

\footnotetext{
${ }^{18}$ BLECUA, J.M. (ed.): Cancionero de Pedro Marcuello, Zaragoza 1987.

${ }^{19}$ Reproducido en VICENTE CASCANTE, I.: Heráldica General y Fuentes de las armas de España, Barcelona 1956, p. 466
} 
13. Divisas personales de los Reyes Católicos recogidas en el

Cancionero de Pedro Marcuello, siglo $X V$

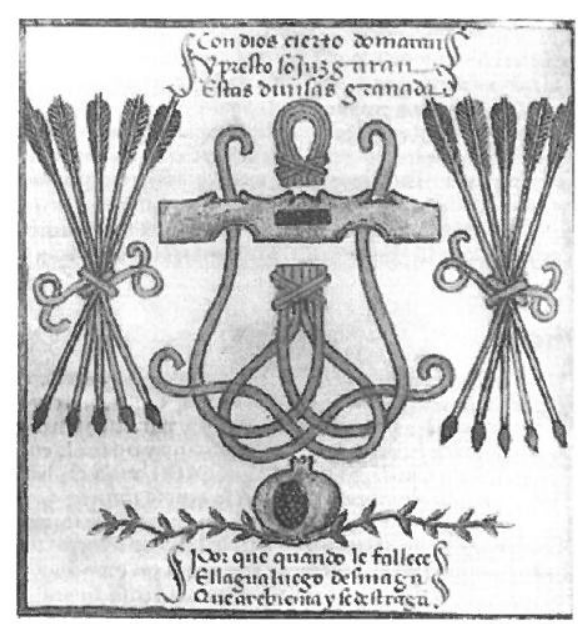

14 y 15 . Granadas en diferentes detalles ornamentales de Santo Tomás el Real, en Ávila
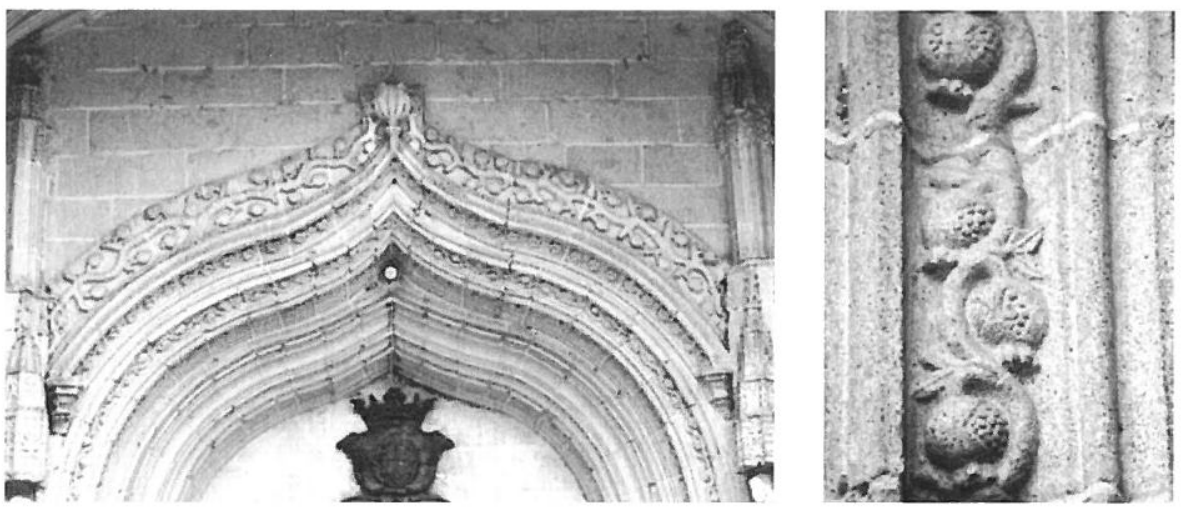

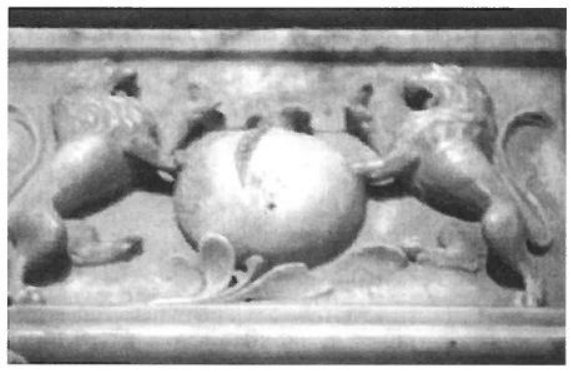

16. Emblema de granada soportada por leones en el sepulcro de los Reyes Católicos

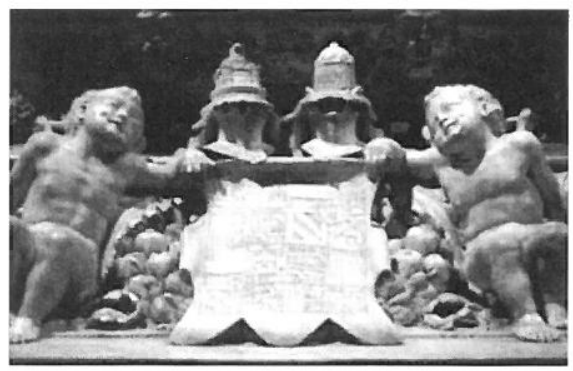

17. Armas de la reina Juana y de Felipe el Hermoso, con dos yelmos a la manera alemana, en su sepulcro 
- artículos La granada, símbolo de reyes y de la monarquía española

18. Fachada del Colegio de San Gregorio en Valladolid, fundado por los Reyes Católicos, con un granado como soporte a sus armas

Tomás de Ávila, que custodia los restos de su primogénito el príncipe don Juan (FIGS. 14 y 15). Protagonismo destacado, aunque secundario, adquiere la granada en el propio diseño del magnífico panteón de los Reyes en la Capilla Real de Granada, la encontramos como simbolo exento soportada por leones rampantes entre la iconografia del mismo

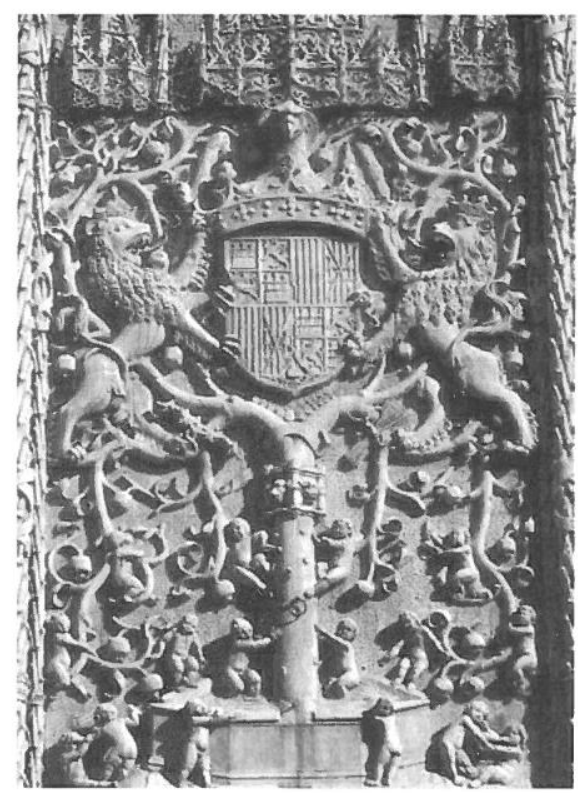
(FIG. 16) y en un amplio entado en punta incorporada al cuartelado de sus armas, en que destaca su exquisito diseño. En el panteón de la reina doña Juana y su esposo Felipe el Hermoso, sus respectivas armas -compuestas detalladamente en un doble contracuartelado- están labradas en una cartela que descansa sobre un lecho de granadas ( $F / G$ 17), metáfora que no debe ser ajena a la propia naturaleza de la concepción de la obra.

Pero la obra más destacada, en que las ramas de granado son elemento iconográfico fundamental, es el gran árbol de granado de la fachada del Colegio de San Gregorio en Valladolid (FIG. 18)). Su magnífico diseño y complejo programa iconográfico se llega a atribuir al propio Gil Silóe ${ }^{20}$, aunque los arquitectos fuesen de la categoria de Juan Guas y Simón de Colonia. Un gigantesco granado nace de una fuente desbordada de niños jugando y trepando a sus ramas; las ramas del árbol abrazan el escudo de los Reyes Católicos, soportado suplementariamente por dos majestuosos leones rampantes coronados, además de la clásica águila nimbada de San Juan. Los rasgos principales de su diseño nos remiten a la obra de Silóe en la cartuja de Miraflores, los sepulcros de los padres de la reina, su hermano el infante Alfonso y posteriormente el altar mayor (FIGS. 19-21). La propia forma del árbol, abierto en dos partes para recoger el escudo, es la misma de las armas de cada uno de los esposos en el altar, los rasgos de los leones de soportes son muy similares a los del

${ }^{20}$ YARZA LUACES, J.: Los Reyes Católicos. Paisaje artístico de una monarquía, Nerea, Madrid 1993, p. 216. 

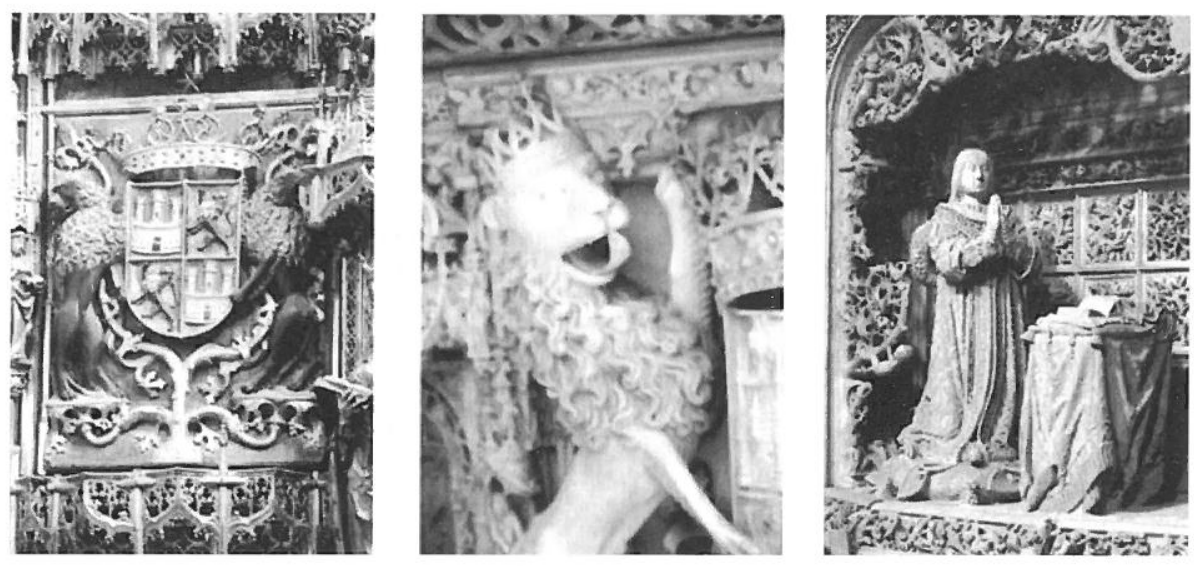

19 - 21. Cartuja de Miraflores en Burgos: Armas de Juan II en altar mayor, detalle de los leones como soportes de las armas reales y sepulcro del infante don Alfonso

sepulcro y los niños trepando por las ramas son los mismos que suben por las ramas de cardos que rodean la imagen orante del infante.

A partir de esta época de esplendor iconográfico de la granada que se vivió con los Reyes Católicos, sin duda atraídos emotivamente por este símbolo que puso en juego el monarca anterior -hermanastro no especialmente querido por ellos-, la granada fija su presencia en la heráldica real española incorporándose a sus armas. "Es la única vez que un territorio reconquistado tiene una expresión heráldica"21. Sin embargo no era éste el emblema del Reino de Granada. Los últimos reyes nazaríes habian creado sus propias armas heráldicas al estilo europeo: de sinople, una banda de plata cargada de una inscripción coránica, según se hallan labradas en la Alhambra (FIG. 22) ${ }^{22}$. Pero se prefirió crear un nuevo emblema parlante, tanto para

${ }^{21}$ MENÉNDEZ PIDAL DE NAVASCUÉS, F.: Heráldica medieval española... op. cit. Hidalguía, Madrid 1982, p. 202. "El primer testimonio de la incorporación de la granada a las armas reales se ha dicho hayarse en un sello de placa de Fernando el Católico sobre un documento fechado en Zaragoza el 30 de agosto de 1492. En las monedas, la granada no aparece hasta las Ordenanzas dictadas en Medina del Campo, en 1497, sobre cómo se ha de labrar la moneda. La moneda de oro que se llamará excelente de la granada, llevará las armas reales -no dice la Granada- y el águila y el lema Sub umbra alarum tuarum protegenos. Pero la referencia en el nombre de la moneda está en relación con las armas, pues en el escudo se incluye la granada, en gran tamaño, como cosa nueva, de la manera conocida: un entado en punta muy rebajado". MENÉNDEZ PIDAL DE NAVASCUÉS, F. "El escudo", en Símbolos de España, Centro de Estudios Políticos y Constitucionales, Madrid 2000, p. 173.

${ }^{22}$ Azulejo del Salón de Justicia en la Alhambra, hecho en Málaga en el siglo XIV. LEAF, W. PURCELL, S.: Heraldic symbols. Islamic insignia and western heraldry, Victoria and Albert Museum, London 1986, p. 93. 


\section{Emblema de los reyes del reino nazarí de Granada, en azulejo de la Alhambra hecho en Málaga en el s. XIV}

designar los nuevos territorios sobre las armas reales, como para otorgar a los descendientes de los monarcas árabes que se convirtieron al cristianismo. De azur, cinco granadas de oro son las armas

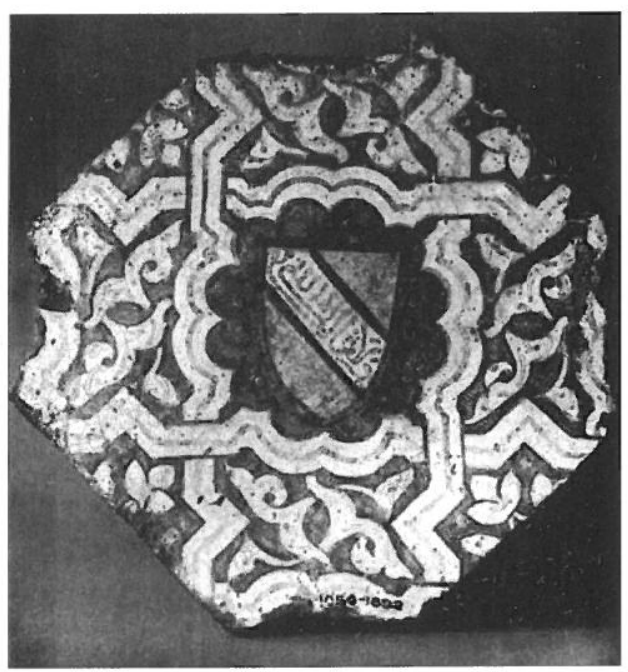
concedidas por la reina en 1503 al bautizado como don Pedro de Granada, nieto de uno de los reyes árabes ${ }^{23}$.

Existe otro testimonio de la concesión de la granada como armas personales, que otorgó el rey Fernando en 1515 a Sir Henry Guilford, que se habia distinguido junto a otros caballeros ingleses en la campaña de granada, para que la incluyera en un cantón sobre las que él ya tenía. Su representación se corresponde con el símbolo empleado a partir de los Reyes Católicos, pues la granada es de sinople y se halla sobre campo de plata, y se encuentra en el College of Arms de Londres ${ }^{24}$. Íñigo González de Mendeja, que se distinguió en la conquista de Granada, llevaba el cuartelado entero de Castilla y León, sobre un águila coronada acompañada de dos granadas ${ }^{25}$.

La granada se convierte en un motivo decorativo habitual en la ornamentación de las obras reales. En varias salas de los Reales Alcázares de Sevilla ${ }^{26}$ encontramos azulejos con una especie de laurea o corona con motivos vegetales que integra granadas. Un sembrado de granadas cubre también un repostero con las armas de Fernando el Católico ${ }^{27}$.

\footnotetext{
${ }^{23}$ Real Academia de la Historia, Colección Salazar, B-86, fol. 66v.

${ }^{24}$ DENNYS, R.: The Heraldic Imagination, London 1975, pp. 30-31. Citado por MENÉNDEZ PIDAL DE NAVASCUÉS, F.: "El escudo... op. cit. p. 174.

${ }^{25}$ MENÉNDEZ PIDAL DE NAVASCUÉS, F: Heráldica Medieval Española... op. cit. p. 256.

${ }^{26}$ Entre ellas el vestíbulo donde están las taquillas.

${ }^{27}$ Citado y reproducido por MENÉNDEZ PIDAL DE NAVASCUÉS, F.: "El escudo... op. cit. p. 180.
} 
23. Corona de Isabel la Católica, compuesta de ramas y el fruto de la granada, en la Capilla Real de Granada

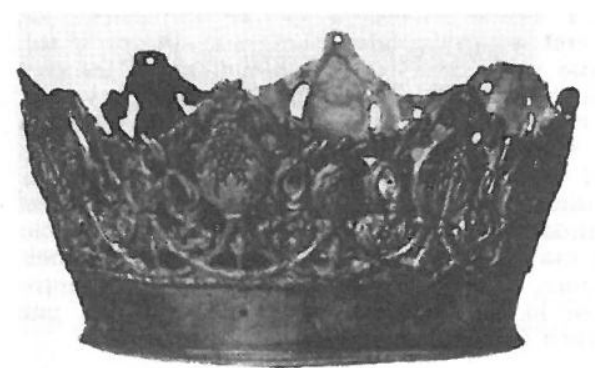

La granada es, por otra parte, el simbolo que genera la corona de Isabel la Católica que se conserva en la Capilla Real de Granada (FIG. 23) ${ }^{28}$. Obsérvese la solución dada por el orfebre a la estilización del fruto, que culmina en tamaños alternos el entrelazado de sus ramas. Este motivo que da forma a la corona se ajusta perfectamente a la iconografía que impera en el reinado de los Reyes Católicos en pleno Renacimiento. "Por el simbolismo del nivel, la corona no sólo se halla en lo más alto del cuerpo (y del ser humano), sino que lo supera; por eso simboliza, en el sentido más amplio y profundo, la propia idea de superación. Por eso se dice de todo cumplimiento perfecto y definitivo "coronar una empresa". Así la corona es signo visible de un logro, de un coronamiento, que pasa del acto al sujeto creador de la acción. Al principio las coronas se hacian de ramas de diversos árboles, por lo que integran, como símbolo secundario, el de la especie correspondiente"29.

La figura de la granada, en oro y con piedras preciosas o perlas engarzadas, se convirtió en el más preciado objeto que regalaron los Reyes Católicos a escogidos y distinguidos personajes. La costumbre pudo partir del regalo que hizo Fernando el Católico a Isabel, de una granada de oro con un diamante y un rubi engastado además de una serie de perlas ${ }^{30}$. En 1482 hay constancia de que dieron al duque de Viséu, en Córdoba, un collar y una granada -que sería de oro- adornados con perlas $^{31}$.

Pero el caso más destacado en que este especial regalo tuvo una mayor trascendencia fue la que le entregaron a su consuegro el emperador Maximiliano de Austria, padre de los esposos de sus dos hijos mayores, que adoptó ese símbolo como divisa personal suya.

\footnotetext{
${ }^{28}$ Reproducida en CIRLOT, J.E.: op. cit. Barcelona 19856, p. 146.

${ }^{29}$ Ibidem.

${ }^{30}$ Memorias de la Real Academia de la Historia, tomo VI, Madrid 1821. Elogio de la Reina Católica Doña Isabel, por Don Diego Clemencín, p. 337. Pieza citada en MENÉNDEZ PIDAL DE NAVASCUÉS, F.: "El escudo... op. cit. p. 171.

${ }^{31}$ Ibidem.
} 


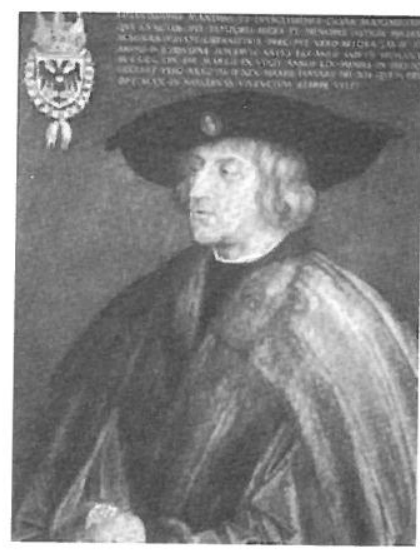

24. El emperador Maximiliano I con su divisa personal, la granada, pintado por Durero

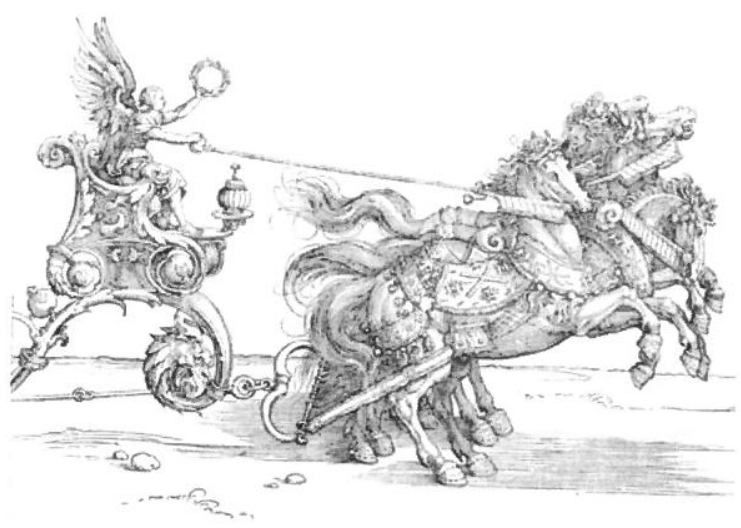

25. Carro de la Victoria, de Durero, segunda estampa de la imagen del matrimonio de Maximiliano I en Borgoña

A partir de la granada de oro y piedras preciosas que le habian regalado los Reyes Católicos, Maximiliano decidió adoptarla como divisa personal. Es curioso verle en diferentes retratos con la granada en las manos, a modo de la esfera del orbe que simbolizaba el poder del monarca.

Entre las numerosas imágenes que componen el amplio programa iconográfico emprendido por Maximiliano I, para difundir una imagen grandiosa que perdure, hemos de destacar el retrato que le hizo Alberto Durero, con la granada (FIG. 24) ${ }^{32}$. EI mayor mecenas de las artes del grabado, dados los limitados recursos para realizar grandes obras de arquitectura, pintura o escultura, tuvo a sus servicios al más importante grabador de la historia. Entre las diversas representaciones del mismo a modo de cortejo triunfal, en carros inspirados en la mitologia romana y en arcos del

\footnotetext{
${ }^{32}$ Retrato de Maximiliano, óleo sobre tabla, Kunsthistorisches Museum, Viena. Según apostilla Checa, el pintor acudió en el verano de 1518 a la Dieta de Augsburgo como representante de la ciudad imperial de Nüremberg, y allí realizó un dibujo del rostro del emperador (Viena, Albertina). Éste sirvió de base al famoso Retrato de Maximiliano (...) realizado ya en 1521, cuando el emperador había fallecido. (...) en su mano la granada, uno de los símbolos del poder favoritos de Maximiliano. Esta, tanto puede aludir al globo imperial, uno de los atributos de este tipo de majestad, como a la virtud de la modestia de su posesor (ya que la granada es rica, brillante y sabrosa en su interior y de sencilla apariencia exterior). Junto a la granada, el escudo y la larga inscripción acompañan a esta imagen, en la que lo más importante, sin embargo, es el gesto y la actitud del retratado que por sí solos constituyen un magnífico emblema político. CHECA, F: Alberto Durero, Historia16, Madrid 1993, pág. 112.
} 
26. Escudo con la divisa personal de Felipe I, el Hermoso, en el Real Monasterio de las Huelgas

triunfo destacamos aqui una de las estampas más bellas realizadas por Durero para la magnánima obra El triunfo de Maximiliano, compuesta por 137 xilografías y realizadas por su taller, representando el

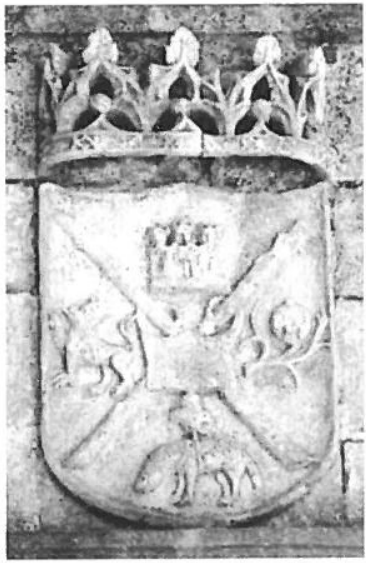
fastuoso cortejo (ca. 1515-18). Durero realizó la principal, que se componía de dos estampas El matrimonio de Borgoña llevado por el Carro de la Victoria, de la que sólo se conserva en la Biblioteca Nacional de Madrid la mitad del carro (FIG. 25) que vemos ornamentado ya con la divisa de la granada y que es la de mayor dinamismo y fuerza expresiva ${ }^{33}$.

La famosa Copa de Maximiliano, cuyo diseño se atribuye a Durero, en el Kunsthistorisches Museum de Viena, está compuesta en su base de una serie de granadas rajadas.

En la fachada de la portería del Real Monasterio de las Huelgas en Burgos tenemos cuatro escudos de armas que indudablemente representan a los reyes como únicos patronos del mismo. Destaca entre ellos, el primero, por ser el único que no reconocemos claramente, además de las armas plenas de Castilla de su fundador Alfonso VIII, el cuartelado de Castilla y León de Fernando III como reunificador de los dos reinos, el clásico contracuartelado de los Reyes Católicos con Granada (FIGS. 3032). Se trata de las variantes fundamentales de las armas reales de Castilla desde el fundador del monasterio y, evidentemente, las colocadas anteriormente a ellas hacen alusión a la divisa que trajeron los austrias con Felipe el Hermoso (F/G. 26). Se sabe que don Felipe, hijo de Maximiliano I y yerno de los Reyes Católicos, empleaba como divisa personal la cruz ecotada de San Andrés -como símbolo de la Casa de Borgoña a la que pertenecía por su madre- con un eslabón brochante del Collar de la orden del Toisón de Oro, con la piel de carnero pendiente -como símbolo de la casa paterna-. Así la tenemos en su sepulcro en la Capilla Real de Granada. ${ }^{34}$ Queda

\footnotetext{
${ }^{33}$ HUIDOBRO, C.: Durero grabador, Ministerio de Educación y Cultura-Biblioteca Nacional/Electa, Madrid 1999, pp. 44-45

${ }^{34}$ Su primogénito y sucesor el emperador Carlos las trajo igualmente, sin el toisón pendiente y coronadas, en una primera época hasta que las sustituyó por las que le caracterizan personalmente, las columnas con el "Plus Vltra" que le creó Marliani. Ambas divisas pueden
} 


\section{2: artículos La granada, símbolo de reyes y de la monarquía española}
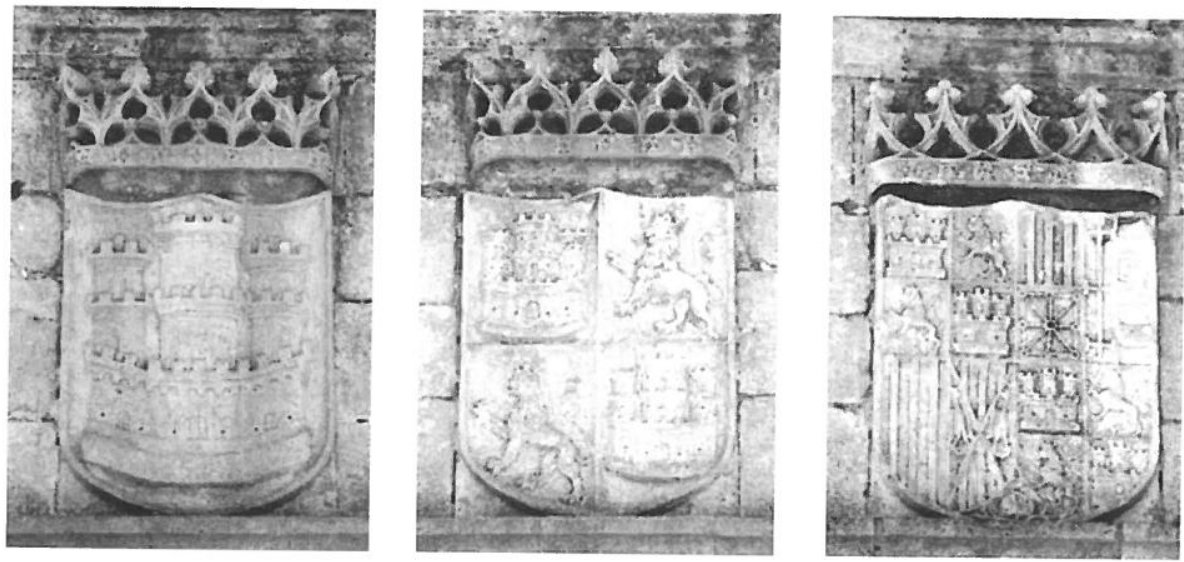

27 - 29. Resto de las armerías en la fachada de la portería del Real Monasterio de
las Huelgas, en Burgos

patente, por tanto, que las armas del primer escudo, de esta serie de la fachada de Las Huelgas, corresponden a don Felipe, como primer rey de la nueva dinastía austríaca que añade, al toisón que ya ocupa uno de los cantones de la cruz, los elementos que considera principales de las armas de sus predecesores: Castilla, León y en tercer lugar Granada ${ }^{35}$. En definitiva, el emblema del primer escudo no se trata de las armas del Reino, como en los casos restantes porque conocemos cuales eran, sino unas armas personales -como la banda engolada de Juan II- o una divisa personal de la que ya conocíamos su composición, a falta de la adición de estos tres elementos.

Una de las hijas pequeñas de los Reyes Católicos, la infanta doña María (14821519), casada con Manuel I de Portugal, al quedar viudo de su hermana mayor la infanta Isabel, trae como divisa personal tres ramas de granado atadas por un cordón terminado en borlas, con sus raíces, hojas y flores. Se cuenta que estas ramas tenian relación con unas pequeñas ramitas de granado que su madre la reina Isabel solía llevar prendidas del vestido ${ }^{36}$. En su sepulcro del monasterio jerónimo de Nuestra

verse en la fachada de la Universidad de Alcalá, junto a sus armas, como fundador y patrono de la misma.

${ }^{35}$ Por otra parte, esta división creada por la propia cruz de Borgoña en aspa, sin ser particiones propiamente dichas, es muy empleada a partir de Fernando el Católico en el área de influencia aragonesa. Las propias armas de Aragón-Sicilia se cuartelan en aspa o frange y la misma enseña de don Fernando es un gironado de plata y sable, como se conserva en memoria del mismo en la bandera de Ceuta.

${ }^{36}$ SIMAS ALVES DE AZEVEDO, F. de: "Empresa e armas duna filha dos Reis Católicos", en Hoja informativa del Instituto Internacional de Genealogía y Heráldica, año VI, núm. 124, Madrid 1959. Citado por CEBALLOS-ESCALERA, A.: op. cit. pág. 677. 
30. Badges de Catalina de Aragón, que recoge la rosa Tudor de la dinastía inglesa y la granada hispánica
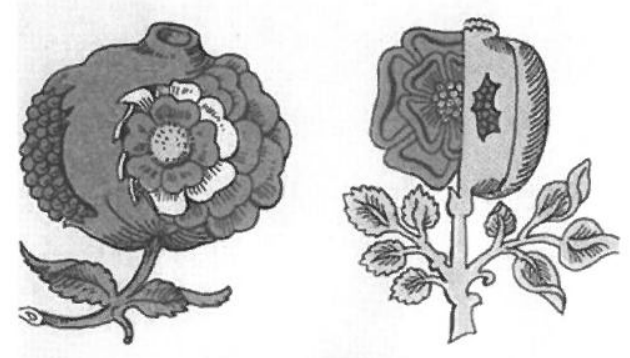

Señora de Belem hay dos escudos sostenidos por un ángel, en uno están sus armas y en el otro su divisa personal. El mismo emblema se repite en la decoración de la iglesia y el convento y también en el convento de Cristo en Tomar.

La hija menor de los Reyes Católicos, la Infanta doña Catalina (1485-1536), como esposa de Arturo -Principe de Gales- y de Enrique VIII trae por armas un escudo partido, de sus respectivos esposos con las armas de sus padres. Como era tradicional en Inglaterra, Catalina emplea como badge o divisa personal el haz de flechas de su madre y, sobre todo, la granada sobre fondo verde, como la traía Enrique IV. Como soporte del mismo incorpora el águila de San Juan, aportada por su madre a las armas paternas, que acompaña en su escudo de armas al león del soporte real de Inglaterra. Esta última figura trae en las armas el lema real DIEU ET MON DROIT y el águila trae el TANTO MONTA. El conjunto se representa sobre una terrasa, como es habitual en la herádica anglosajona, de la que brotan la doble rosa Tudor -de plata y gules- y la granada -de oro-. En otra versión de estas armas en un manuscrito del College of Arms de Londres trae, en lugar de la terrasa, un mantelete alrededor del escudo y del que salen entrelazadas la rosa Tudor y la granada (FIG. 31)

El primer badge o divisa es también una especie de partido entre la rosa Tudor y la granada ( $F / G .30)^{3 s}$. Una enseña que trae su emblema está partida verticalmente de rosa y verde y en cada color trae, respectivamente, la doble rosa y la granada, cuyos tallos se entrelazan bajo la corona real inglesa ${ }^{39}$.

\footnotetext{
${ }^{37}$ Lord HOWARD DE WALDEN: Banners, standards and badges from un Tudor manuscript the College of Arms, London 1904, pp. 15 y 16.

${ }^{38}$ NEUBECKER, O.: Le Grand Livre de L'Héraldique.L'histoire, l'art et la science du blason, Bordas, Bruxelles 1977, p. 211.

${ }^{39}$ MENÉNDEZ PIDAL DE NAVASCUÉS, F: Heráldica Medieval Española... op. cit. p. 210. María Tudor, la desposeída hija de doña Catalina, traía por armas de soltera un cuartelado: $1^{\circ}$ y $4^{\circ}$ de Francia, $2^{\circ}$ de Inglaterra y $3^{\circ}$ de los Reyes Católicos, timbrado con la corana de príncipe inglesa y soportado por el lebrel blanco de Richmond y el águila negra de San Juan. Su divisa era la doble rosa Tudor, partida dimidiada con un semicírculo, partido a su vez de verde y azul, con el haz de flechas atadas con un lazo blanco; todo ello rodeado de rayos y timbrado con la corona de príncipe. Ibidem.
} 
31. Armas de Catalina de Aragón, como esposa de Enrique VIII de Inglaterra

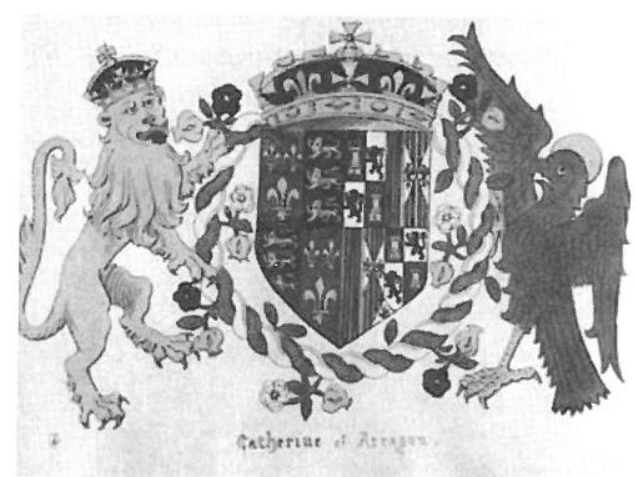

La codificación que presentan la rosa y la granada se ajusta a las reglas heráldicas. Éstas, como es sabido, seleccionan los rasgos más significativos de la figura, estilizándola o esquematizándola. En el interior del campo del escudo las leyes de la perspectiva quedan abolidas. La misma anulación de la perspectiva se da, por extensión, en el dibujo de las empresas heráldicas, tanto si acompañan a las armas, como si aparecen en composiciones independientes, como en este caso.

Analizaremos por separado cada uno de los elementos que componen este emblema. La rosa heráldica seria reconocida como tal a primera vista. Ello se debe a que está contemplada desde una perspectiva muy original. Para dibujar la rosa, la heráldica ha elegido la altura. Esta figura está vista desde arriba y en un punto ideal, situado en la vertical misma de su centro. El resultado es una silueta de contorno circular y forma polilobulada, que se inscribe en un pentágono. Muy distinta, como puede apreciarse, de la configuración convencional convertida ya en estereotipo, que nos presenta la rosa de perfil. El enfoque heráldico genera una representación singular y artificiosa. Pero, estéticamente, es de agradecer esa privilegiada visión de la flor. Su codificación heráldica y su composición en doble rosa nos permiten reconocer la identidad de la rosa Tudor, sin necesidad de los esmaltes característicos.

Contrariamente, la granada es representada por la heráldica con un enfoque desde la perspectiva frontal. La visión está mucho más cercana del natural que la anterior. A ello contribuye también la leve inclinación que presenta y el hecho de que se la dibuje rajada, ofreciendo su fruto a la vista. La perspectiva es, en conjunto, mucho menos rígida.

En el emblema dimidiado de Catalina de Aragón -media rosa y media granadaapreciamos cierto carácter 'monstruoso'. No viene éste de su condición heráldica (pues el dimidiado cuenta con gran tradición en la representación del blasón), ni de su naturaleza (ambas son figuras vegetales y de tamaño no muy dispar). En realidad, su 'monstruosidad' radica en el hecho de que se yuxtapongan y se hagan 
32. Ramas entrelazadas de granado y de la rosa Tudor, en la portada del Hotel Reina Victoria en Ronda

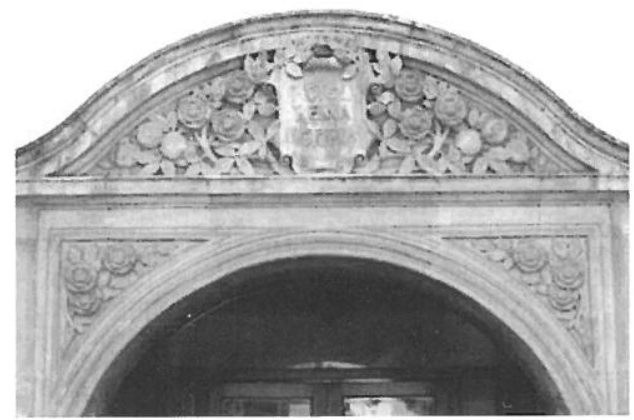

simultáneas en una sola figura dos perspectivas radicalmente contrapuestas (una desde arriba y otra de frente). No hay, pues, paradoja, en el hecho de que cuando el dimidiado se representa artificiosamente, resulta más tolerable (es más natural, porque -valga la expresión- es artificial por naturaleza) y de que, en cambio, cuando se pretende una integración natural de ambos motivos -como se hace en la segunda figura- el efecto sea francamente monstruoso.

La granada y la rama de granado nos llega hasta principios del siglo $\mathrm{XX}$ como símbolo de la Casa Real Española -en Inglaterra-, como se aprecia en el motivo que preside la portada del Hotel Reina Victoria en Ronda (FIG. 32). El hotel fue construido en 1906 por la empresa inglesa Iberian and Mediterranean Hotels Company para responder a la demanda inglesa y norteamericana surgida a partir de las crónicas y dibujos de los viajeros románticos del XIX sobre Andalucía. El diseño arquitectónico del hotel es una simbiosis de estilos, inglés y andaluz, y ese enlace de caracteres no es algo casual sino un objetivo claro del proyecto (FIG. 33). Prueba de ello es el nombre elegido para el mismo Reina Victoria, miembro de la Casa Real inglesa que había contraido matrimonio con Alfonso $\mathrm{XIII}^{40}$. El habitual eclecticismo inglés recoge elementos propios de la casa noble rondeña, con la portada de piedra blasonada sobre el blanco de los muros, e integra el vidriado verde de la cerámica popular andaluza en las tejas del edificio. Por otra parte, la tipología de la acusada pendiente en los tejados, de las ventanas blancas de palillería, etc. son rasgos de la arquitectura inglesa. La portada de piedra que, por el tipo de material y especialmente por el estilo de la misma, debió ser realizada en Inglaterra da un aire distinguido y levemente exótico al conjunto.

\footnotetext{
${ }^{40}$ Esta denominación fue solicitada a S.M. la reina Victoria Eugenia de Battenberg, que concedió la autorización mediante carta del Jefe Superior de Palacio de ocho de octubre de 1906. Pero el nombre de Reina Victoria no hay que olvidar que es al mismo tiempo el de Victoria Eugenia, casada con el rey de España, y su abuela la emblemática Reina Victoria I de Inglaterra, emperatriz de la India, que había reinado hasta unos años antes de la construcción del hotel.
} 


\section{Hotel Reina Victoria a principios del siglo $X X$, situado en la cornisa del tajo de Ronda}

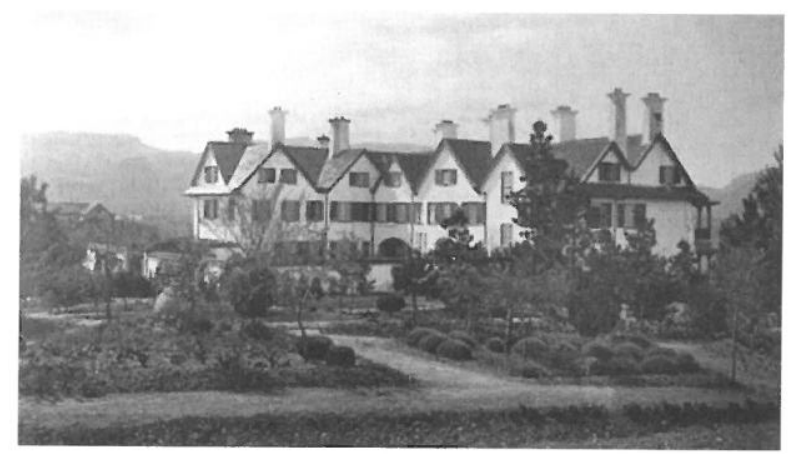

En una época en la que no estaban de moda los escudos heráldicos en las portadas se realiza aquí una tarja con el nombre del hotel. Sin embargo, en los motivos vegetales que la ornamentan encontramos de manera fortuita ${ }^{41}$, cuatro siglos después, el rebrote de las granadas de Catalina de Aragón en sus emblemas reales volvió a Ronda de manos de los ingleses. El autor de la portada comprendia plenamente el alcance simbólico que llegó a tener la granada en su unión con la rosa.

Durante este largo tiempo la granada no perdió su vitalidad iconográfica. En Ronda, concretamente, su imagen permaneció latente entre los detalles de diferentes conjuntos ornamentales. Se utiliza, por ejemplo, en la portada de la casa de los Moctezuma, decorando el cajeado de las pilastras (FIG. 34), y escondida entre el exuberante ornato de la fachada de la iglesia de Santa Cecilia, ocupando de manera modesta el centro de la clave de la portada (FIG. 35).

La clave de que se trataba de las ramas de granado frutadas que se emplearon en la iconografía real inglesa como símbolo de la Casa Real española nos la ofrece el reconocimiento de la rosa Tudor. La figura de esta rosa heráldica especial se aleja de una representación naturalista de un motivo vegetal, al ser una estilización realizada de la heráldica que representa la rosa, vista desde arriba y con cinco pétalos, y que en la rosa Tudor se superponen dos de estas flores en alusión a la unión matrimonial de la dinastía de York y Lancaster, representadas por una rosa blanca y otra roja.

Las ramas de rosal -con sus flores- y las de granado -con sus frutos- aparecen aquí delicadamente entrelazadas. Su función es ornamentar la cartela, a la vez que ilustrar el contenido de la misma, con el nombre del hotel, y enmarcarla en el espacio del tímpano. Estos elementos decorativos, aparentemente triviales, van a tener una

\footnotetext{
${ }^{41}$ Véase al respecto: GARCÍA GARRIDO, S.: "El diseño simbólico de la granada en el hotel Reina Victoria (Ronda)", en Jábeja n 76, Málaga 1996, pp. 72-82.
} 


Dartículos $\quad$ Sebastián García Garrido
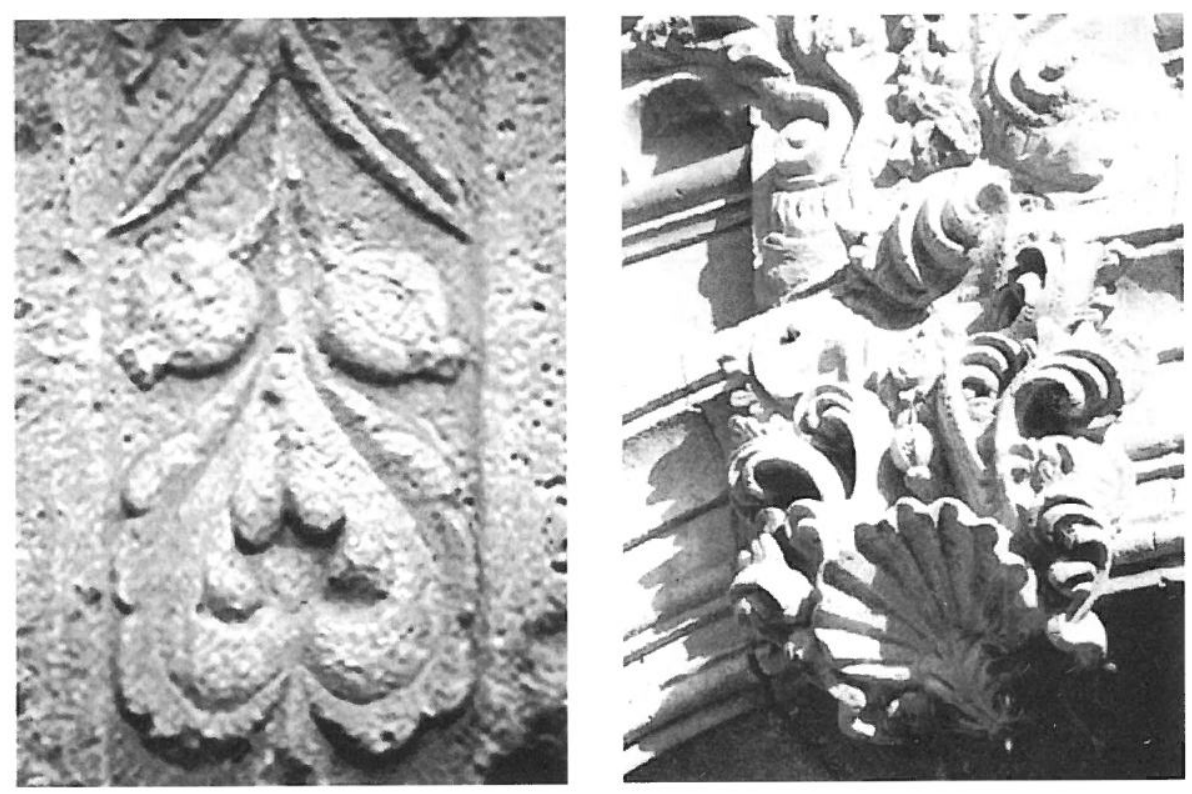

34 y 35. Granada como motivo de ornamentación en portadas de Ronda

enorme carga simbólica y artística que les confiere plenamente la condición de signos iconográficos.

En consecuencia, este símbolo heráldico de la Casa Real inglesa nos define que las ramas de granado -que en cambio se presentan de modo naturalista- no son un simple motivo ornamental sino el símbolo de la Casa Real española en Inglaterra. En primer lugar se percibe la vinculación dinástica, entre ambas casas reales, en el siglo $\mathrm{XX}$ pero también en el XVI. En el entrecruzamiento de las rosas y las granadas se percibe también la alusión territorial: la unión entre lo británico -antes lo inglés- y lo español -antes, en el XVI, lo hispánico- que tan bien se prestaba a los intereses de la compañia. En un nivel más restringido es igualmente expresión del encuentro entre lo inglés y ese territorio romántico que constituye el antiguo Reino de Granada -y concretamente Ronda- fruto de una visión exótica de Andalucía. La granada es reconocida también hoy dia como símbolo de Andalucia en Estados Unidos ${ }^{42}$.

La decidida vocación artística de la portada hace que tanto el texto verbal como el lenguaje visual se vuelvan en ella estéticos. La granada, como signo artístico que es, y a diferencia del puramente lógico, tiene una significación múltiple y radiante. La importancia simbólica de su diseño se ramifica, como hemos visto, a través de la historia, la cultura y el arte. 